\title{
Gear geometric control software: Approach by entities
}

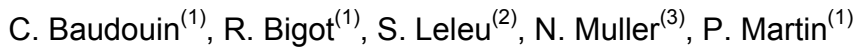 \\ (1) LGIPM, EA 3096 - ENSAM CER Metz - 4, rue Augustin Fresnel - 57078 Metz Cedex 03 - France \\ (2) L2MA - ENSAM CER Lille - 8, boulevard Louis XIV - 59046 Lille Cedex - France \\ ${ }^{(3)}$ ASCOFORGE SAFE Rue de Verdun - 57300 Hagondange - France
}

\begin{abstract}
To develop Net Shape parts by forging, process planing must take design, production, heat treatment and control difficulties into account the earliest it's possible. In this perspective, we propose to present an aspect of our work, made in collaboration with an industry, which deals with the dimensional control of the functionality of forged straight bevel gear for car differentials.

To study the functionality of the gear, we have split it up into entities which could be looked from different views (designer, manufacturer, metallurgist, ...). The metrologist is interested in the geometry of the entities. After the measurement on coordinate measuring machine, the development of a software enable us to obtain the standard deviations of gears by analysing the position defaults or the intrinsic defaults of all entities.

This new approach enables to qualify the whole process planning. Then, the development reported in this paper deals with the eccentricity between the Net Shape teeth and the assembly surfaces manufactured before heat treatment.
\end{abstract}

\section{Keywords:}

Bevel gear, geometric control, precision manufacturing, process capability, integrated design

\section{INTRODUCTION}

Since the big companies extend their knowledge and their responsibilities over their sub-contractor, the relations between customers and suppliers move to a partnership. Then, the supplier controls more and more the design, the manufacturing and the inspection of its parts. In integrated design, functional specifications have tendency to replace design drawings. So, the supplier should not be satisfied any more to deliver a product in conformity with a design drawing, but he must respond to functional requirements [1]. We develop methods to ameliorate the functional quality of a product during the cycle of its design, its manufacturing, its heat treatment and its control.

Our work, undertaken in partnership with industry, deals with the net shape forged spur bevel gear from an automotive differential. On net shape forging gears, the active surfaces of the teeth are obtained directly by forging without tooling. In the context of integrated design and manufacturing, we must use a model that could give the good information at the good person and at each moment of the production process. Such a model must adapt to various points of view (designer, manufacturer, metallurgist, metrologist, ...).

As we reason on the functionality of the product, we have split up it into elementary functional entities. These entities are mainly characterised by metallurgist and geometric criteria [2]. Each protagonist around the realisation of the gear will have a common language referring to these entities, so the dialog between them will be easier. The metrologist has the role of checking that product respond to functional requirements. To do that, he must give the geometric information of the entities previously defined, and the other participants will understand easily these characteristics with regards to the functionality of the part. In this paper, we present our method based on entities from the point of view of the metrologist.

\section{THE CONTROL OF GEARS ACCORDING STANDARD REFERENCES}

As for all mechanic parts, the functional tolerancing of teeth concern the geometric specifications on features. The designer must manage the difficult translation from the guaranty of a product to assume a function into geometric specifications. Then, the metrologist checks that the real geometry is in the volume determined. Also, he must evaluate precisely the geometric deviations from the nominal definition to transpose them into qualitative variations of the functionality. In an integrated design context, these data enable to act on process planning during the designing and the manufacturing.

So for gears, in addition to the classic geometric specifications (dimensions, orientations, ...), the tolerancing needs particular specifications (single pitch error, pitch variation, tooth profile error, etc ...) defined by Standards to traduce the functionality of meshing $[3,4,5]$.

However, for bevel gears, the pitch deviations are not precisely defined by the ISO Standards. After looking into Deutsche Standards [6] and Japanese Standards [7] which are a little bit clearer on bevel gears, and after our interpretations from cylindrical gear Standards, we can define (Figure 1 and 2):

- Pitch: curvilinear length of pitch circle between two corresponding flanks [4].

- Pitch diameter: diameter of the pitch circle located at the intersection between pitch cone and back cone [4].

- Single pitch error: algebraic difference between real and theoretic pitch calculated on a control circle [3]. The Standard ISO/TR 10064-1 recommends that control must be done approximately at semi-height and semi-width of gear teeth [5].

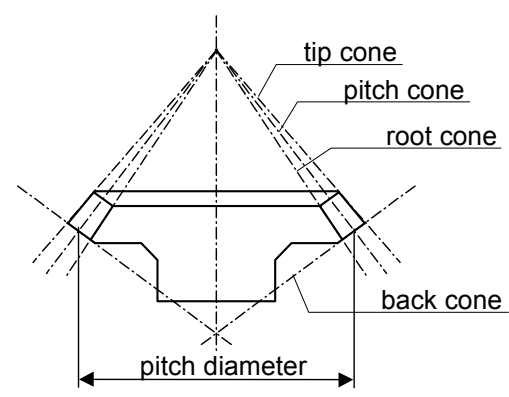

Figure 1: Bevel gear definitions [4] 


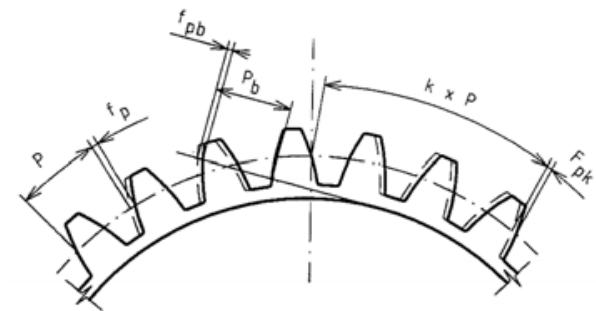

$$
\begin{array}{cc}
\text { P: theoretic pitch } & \mathrm{f}_{\mathrm{p}}: \text { single pitch error } \\
\mathrm{P}_{\mathrm{b}} \text { : base pitch } & \mathrm{f}_{\mathrm{pb}}: \text { single base pitch error } \\
\mathrm{k} \times \mathrm{P} \text { : accumulative pitch } & \mathrm{F}_{\mathrm{pk}}: \text { accumulative pitch erro } \\
\text { (here } \mathrm{k}=3 \text { ) } &
\end{array}
$$

Figure 2: Pitch and pitch errors definitions [5]

The installation of this control was initially made for gear obtained by cutting tool. If the evaluation of errors in one point by flank is enough to make corrections on cutting machine because involute are made by generation, it doesn't enable to explain the real quality of the part functionality. Indeed, the characterisation of the pitch errors from a teeth only onto the control circle isn't representative because the util active surface of the teeth was larger than a point in the middle of the flank. From the functional point of view, effects must be characterised for each angular position during the meshing.

In what concerns us, net shape forged bevel gears, we don't generate teeth with a unique rack for all teeth, but we make teeth by forming. So teeth become independent one from the others. The part is the replication of the die, so one flank can be submitted to a local deformation due to a problem of realisation onto the die. Consequently, results should be very different depending on how we choose the control circle, especially if some flanks have big surface deformations. Then we have developed a new strategy of calculus, applied to gear control, after the measuring of active flanks in several points [8].

\section{APPROACH BY ENTITIES}

\subsection{Conceptual model of entities}

To check the functionality of bevel gear, we have reconsidered the control of such parts, independently from the mean of production we use to obtain them. We defined functional entities to modelise the gear, particularly at a geometrical and metallurgical level. The actual model is the result of a reflection from different points of view (designer, manufacturer, metallurgist, metrologist, ...). This model is transversal, but it is susceptible to evolve so that pertinent information could be put or taken off easily from the different points of views. However, the basic structure is strong enough to work and everybody could bring complements to structure the model (Figure 3).

Based on functional entities of teeth, the elementary entity can be built only on one surface type element (meshing surface, bearing surface, driving surface, limitation surface,,.. )

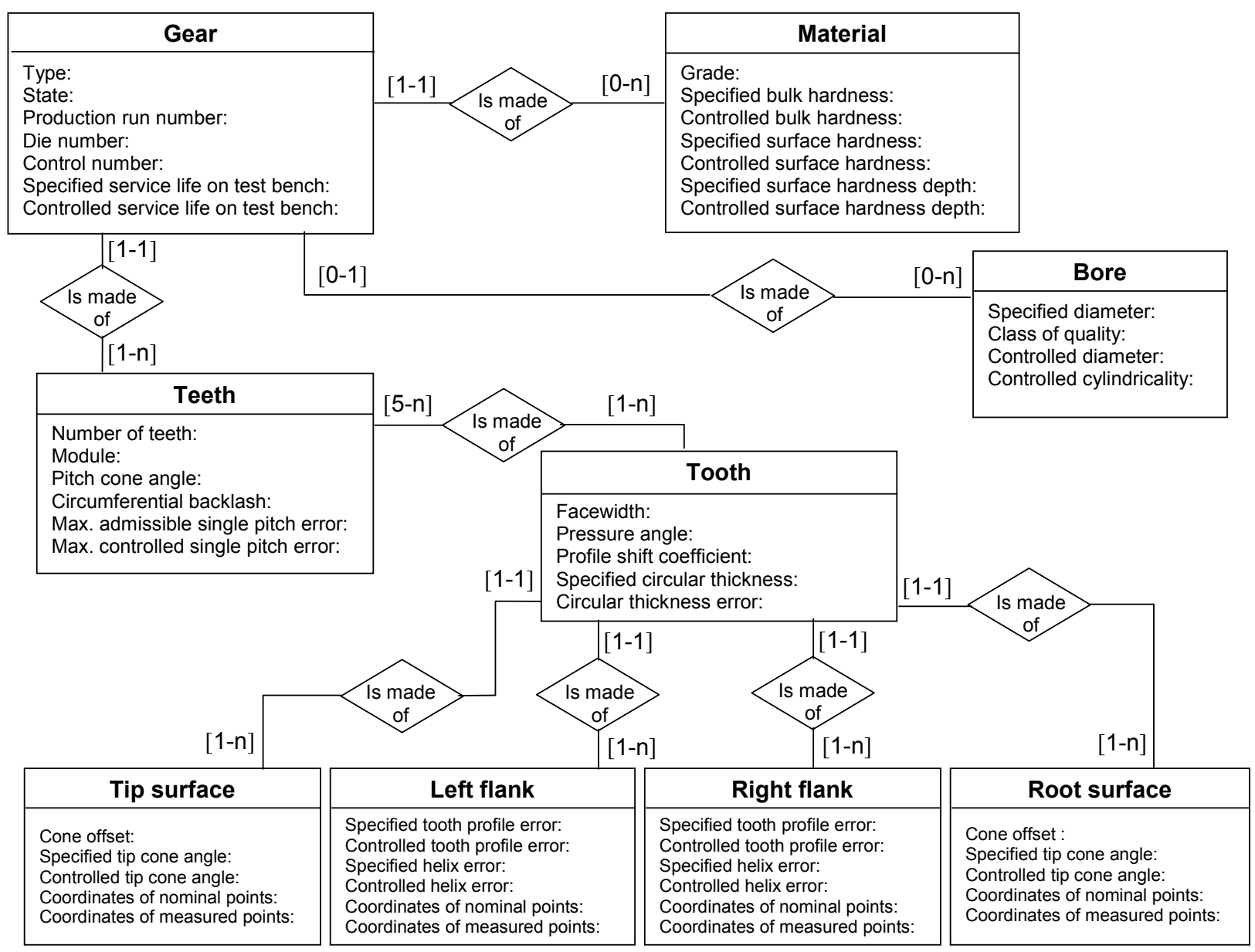

Figure 3: Partial modelisation of a gear with entities 


\begin{tabular}{|c|c|c|c|}
\hline Required characeristics & Source & Protagonist & Value of the characteristic 'State' \\
\hline $\begin{array}{l}\text { State of the gear to control } \\
\text { (State) }\end{array}$ & Production & $\begin{array}{l}\text { Manufacturer } \\
\text { Scheduler }\end{array}$ & $\begin{array}{l}\text { Roughed, calibrated } \\
\text { or heat treated }\end{array}$ \\
\hline $\begin{array}{l}\text { Data of traceablity } \\
\text { (production run number, die number, type, } \\
\ldots \text { ) }\end{array}$ & Production & $\begin{array}{l}\text { Manufacturer } \\
\text { Scheduler }\end{array}$ & $\begin{array}{l}\text { Initial geometry then } \ldots \\
\ldots \text { then roughed } \\
\text { then calibrated then } \ldots\end{array}$ \\
\hline $\begin{array}{l}\text { Nominal geometry } \\
\left(m_{0}, z, \alpha_{0}, x, \text { pitch cone angle, coordinates of }\right. \\
\text { nominal points, ...) }\end{array}$ & $\begin{array}{l}\text { Knowledge management } \\
\text { Computer-Aided Design } \\
\text { Simulations of meshing }\end{array}$ & Designer & Initial geometry \\
\hline $\begin{array}{l}\text { Admissible deviations for geometry } \\
\text { (tolerances: } f_{p}, f_{u}, f_{a}, F_{p}, F_{a}, F_{\beta} \text { ) }\end{array}$ & $\begin{array}{l}\text { Simulations of meshing } \\
\text { Process capabilities }\end{array}$ & $\begin{array}{l}\text { Designer } \\
\text { Manufacturer }\end{array}$ & Toleranced geometry \\
\hline $\begin{array}{l}\text { Nominal mechanics characteristics } \\
\text { (bulk hardness, surface hardness, ...) }\end{array}$ & $\begin{array}{l}\text { General mechanics } \\
\text { Metallurgy }\end{array}$ & $\begin{array}{l}\text { Designer } \\
\text { Metallurgist }\end{array}$ & Initial mechanical resistance \\
\hline $\begin{array}{l}\text { Admissible deviations for mechanics } \\
\text { characteristics } \\
\text { (tolerances: bulk hardness, surface } \\
\text { hardness, ...) }\end{array}$ & $\begin{array}{l}\text { Metallurgy } \\
\text { Process capabilities }\end{array}$ & Metallurgist & Toleranced mechanical resistance \\
\hline
\end{tabular}

Table 1: Initial values needed by the metrologist

Each entity has characteristics that could be geometric or not. From the metrologist's point of view, we are interested by the entities based on geometrical elements. We distinguish entity from element by the characteristics we add at the element. For example, the element "Right Flank" is the set of points in the space closely connected which define geometrically the active flank, but the entity "Right Flank" will be composed by other characteristics as profile error or lead error which are characteristics interpreted and defined in relation with cinematic parameters.

From the functional entities, we rebuilt the gear with macroentities step by step. A macro-entity is an entity that can be split up into macro-entities or elementary entities. For each macro-entity, additional characteristics are added to pass from a surface to a volume, from a geometric volume to mechanic and cinematic characteristics, ...

In this model, the different entities of the macro-entity "Gear" move according to the characteristic "State". Before each state of the design-production-control process, everybody could extract necessary information, do its calculus, and/or do its work. Once the finished state, the participant will give new information that he has obtained and he must corrected the characteristic "State" by the right state corresponding to the gear (initial geometry, calibrated, heat treated, ...) Everybody can carry out its task as soon as necessary information are available so several step could be lead in parallel.

Initial values needed by the metrologist to check gears are sum up in the Table 1 . We could remark that the metrologist mustn't wait the design drawings to do its task. As soon as the numeric definition is available, he could prepare the numeric programming of control on Coordinate Measuring Machine (CMM) before knowing the admissible variations to conserve a good quality of meshing because the calculus of geometric errors is disconnected from the numeric programming.

Once the controls done, the metrologist gives the values of the different characteristics that defined the entities of the gear. The value of the characteristic "State" of the macroentity "Gear" is modified in accordance with the operation of control done. It becomes, for example, "calibrated and geometrically controlled" or "calibrated, geometrically controlled and controlled in mechanical resistance.

\subsection{Operations with entities}

The operations we done on entities apply more precisely to the geometric elements than with the entities themselves. In accordance with the Geospelling model, the operations on the entities are based on the distinction between the ideal geometric elements and the not-ideal geometric elements as well as the existence of six types of operations $[9,10]$.

Let us consider a real gear (not-ideal element). The operation of Partition makes it possible to decompose the whole real gear into elementary geometric elements. On each element, the operation of Extraction gives a discretized image of surface. In other words, the surface of the element considered is not defined any more by an infinite set of points but by a finished set of points. This discrete image of the real gear can be measuring using a CMM. By a theoretical and practical estimation, we previously proved that the level of uncertainty of CMMs was largely lower than the requirements of precision of the bevel gears for forged differential.

Then for each not-ideal discretized element, we associate an ideal geometrical surface of the same type according the criterion of least squares. In addition to the excellent stability and the little of sensitivity of this criterion with the aberrant points, it makes it possible to approach an image of the real functional surface under deformations.

By Collection of geometric elements, we can define the system of references for results examinations in accordance with the indicated specifications. Thus, after the "State" calibrated, the system of references will be aligned on the Collection of active surfaces of teeth, only finished functional surfaces. However, in the "State" delivery, the systems of reference will be aligned on the back plan first and then on the cylinder that better translate the functionality of assembly and meshing.

After we had replaced the gear in the space of the machine, it remains to determine the geometric errors on the gear. The comparison between measured and theoretic points for each entity enables us to calculate two types of errors :

- errors of position and orientation between two elements : the angular position between two associated active flanks gives us the real circular thickness.

- intrinsic form errors to an element : the analysis of the variations between real surface and the associated surface gives the intrinsic defaults like profile or lead error.

By comparison with the nominal values, we determine the circular thickness, profile or lead errors. This approach, generalizable with all the defaults of gears, is coherent with that of Pfeifer [11]. 


\section{DEVELOPMENT OF A SOFTWARE MODEL}

In the perspective to use this method of calculus in an industrial way to check forged gears, we develop a software model in an object-oriented language.

An interface enables the metrologist or the designer to give the different nominal values for the characteristics of the entities making the macro-entity "Gear" (Figure 4). It's possible to choose methods of examination at several levels. The repartition of the set of points (number of profile, and number of points by profile), like the choice to built the system of references (alignment on the teeth, a plane, a cylinder or a sphere and all the combination of this element) could be chosen by the protagonist. Then, a text file named "reference data" is saved. Only one such a file by geometry of gear must be created. These files make a database that could be consulted as many time as necessary.

The second operational aspect concerns the examination of points itself. The association of virtual surfaces onto real set of points and the calculus of position and intrinsic parameters are automated. The global structure shown Figure 5 presents the information flow from the numeric definition to geometrical errors on gear.

The software model uses a standard file of measured points, so it is independent from CMMs. After several tests of compatibility between real and theoretical geometries, the calculus is made and a synoptic of the results appears on screen and on paper if we want. Errors are indicated by values but we work on the integration of charts in the presentation of results.

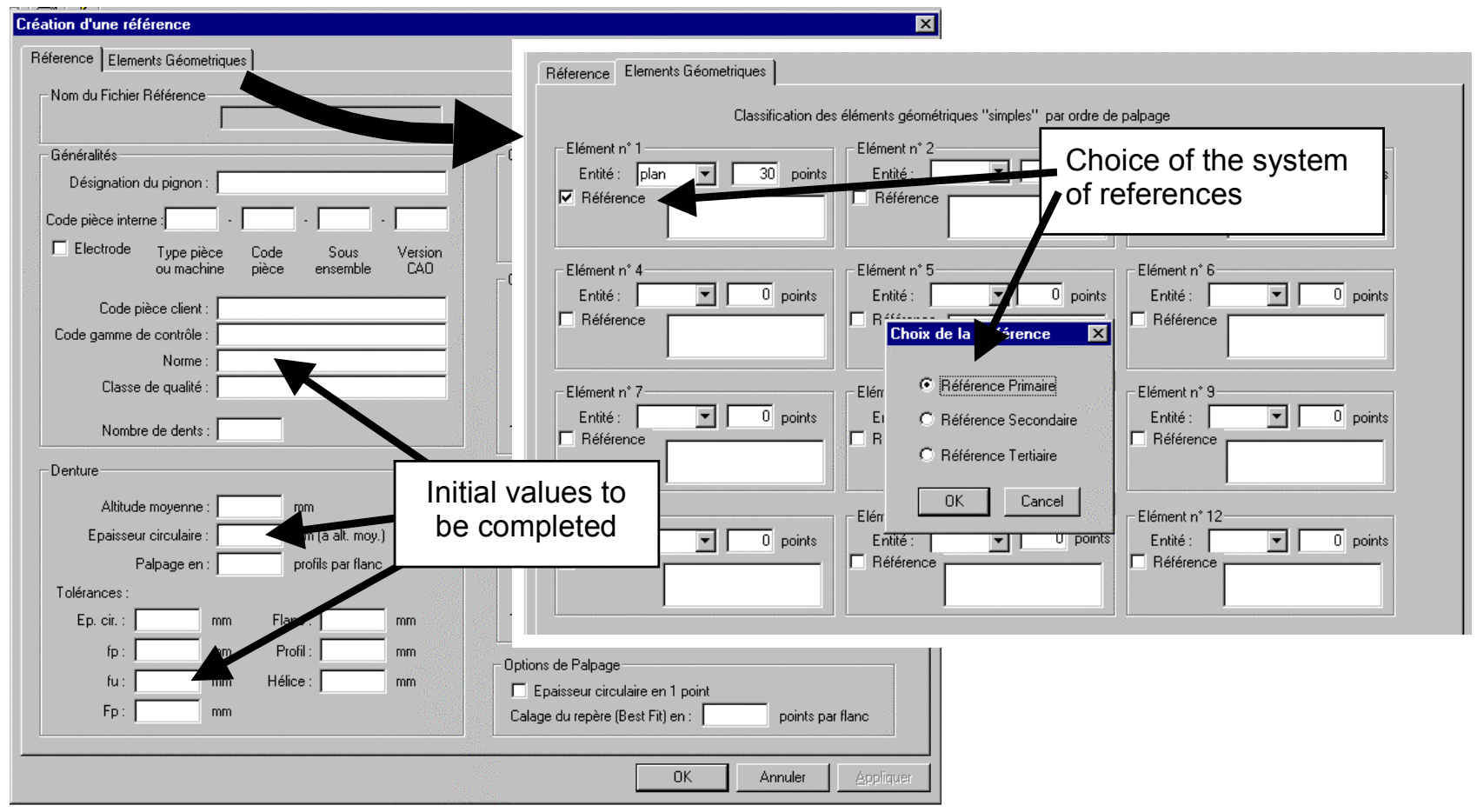

Figure 4: Software interface to give information on reference data

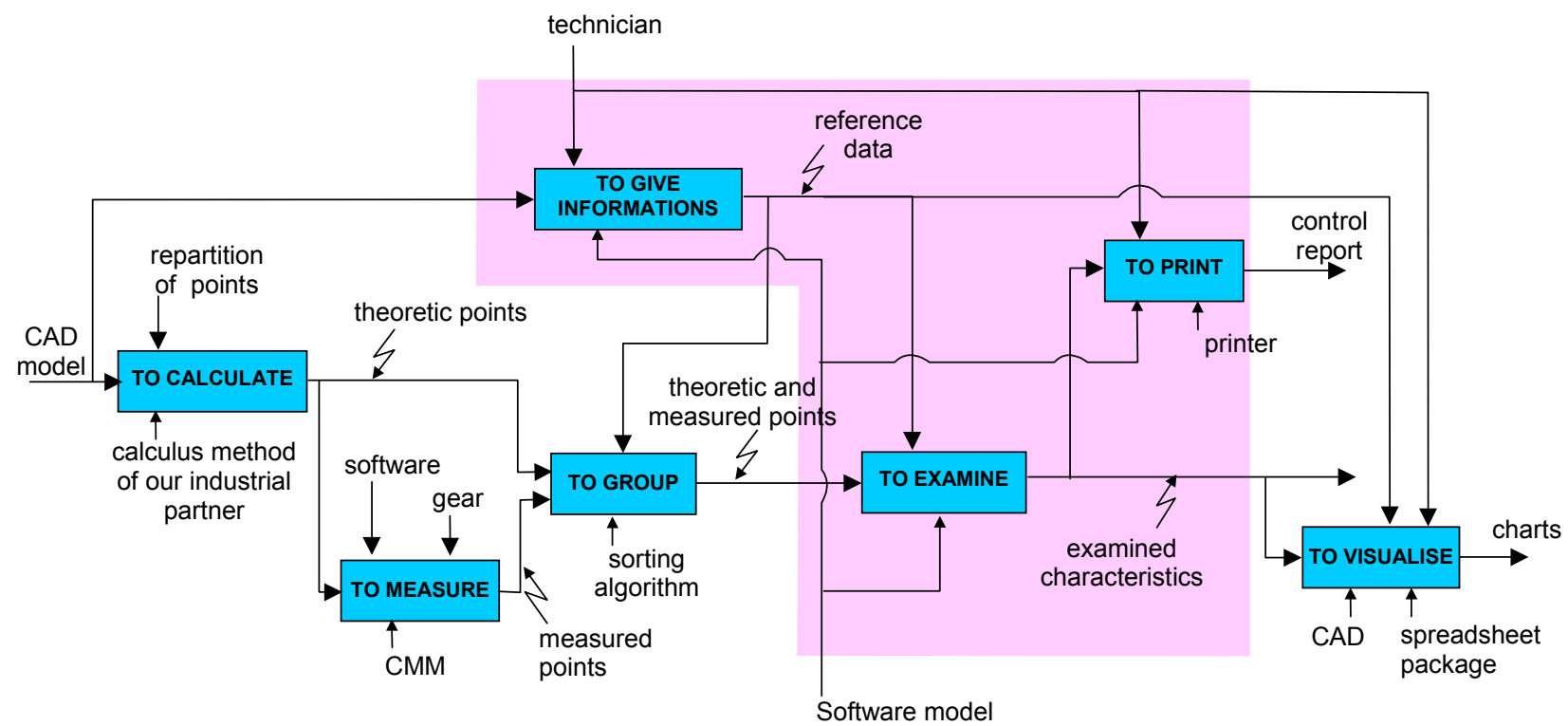

Figure 5: Block diagram of our software model 


\section{USE OF THIS SOFTWARE MODEL IN INTEGRATED DESIGN}

\subsection{Influence of systems of references}

This new approach, associated to a measurement of a gear by multi-step rotation, was first used to qualify measurement process and to identify systematic errors and machine repeatability influences [8, 12]. So, we showed that we could reduce the degree of uncertainties on the announced results. In parallel to the development of the software model, we have optimised the plan of measurement and we have saved half of the time of control. The gain comes from the calculus that is not done during the measurement, and from the possibility of treating a set of points several times without having to measure it again.

With this software model, we can examine the same set of points in different systems of references. After the measurement of a gear, we could show that the choice of the system of references is important to reach at the good conclusion (Figure 6).

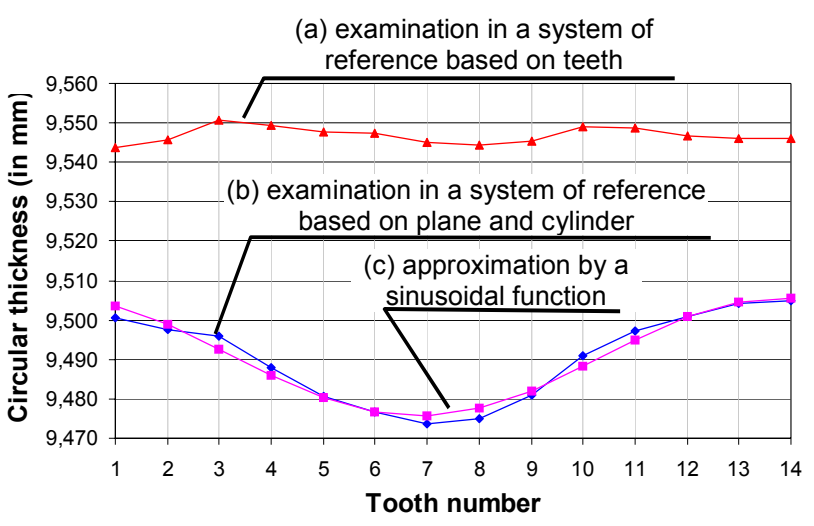

Figure 6: Influence of the system of references for examination

The teeth could be intrinsically good as regard to the circular thickness, because the variations are about $8 \mu \mathrm{m}$ which come from the realisation of dies or from the production process (case a).

However, if we study the circular thickness in a system of references based on the collection of the back plane and the cylinder (case b), we saw a sinusoidal evolution with an amplitude of $30 \mu \mathrm{m}$ (curve c).

This is characteristic of an eccentricity of $47 \mu \mathrm{m}$ between the teeth and the cylinder, the centre of the cylinder being under the tooth number 7 . The distance of $56 \mu \mathrm{m}$ between the two examinations comes from default of positioning of the back plan with regard to the teeth on its axis. This default is worth $76 \mu \mathrm{m}$, value obtained by the calculation of a homogeneous matrix of small displacements.

What is important for the circular thickness, it is the thickness at the root of the tooth to verify the bending strength at the root of the tooth and the circumferential backlash. The examination around the cylinder seems to be more adapted to verify the evolution of the backlash but the examination on the teeth shows that all teeth could equitably resist at the bending strength. A more detailed study on pitch errors will enable to precise the cinematic variations and the real case of charge on teeth in order to know how the effects of eccentricity influence on the time of life of the gear.

\subsection{Influence of heat treatment}

We also remark that the heat treatment change the direction and the amplitude of eccentricity (Figure 7). This phenomenon is perhaps due to the heat flow during the heating or the way of cooling the part. We work onto the heat treatment to improve the quality of the part of this operation.

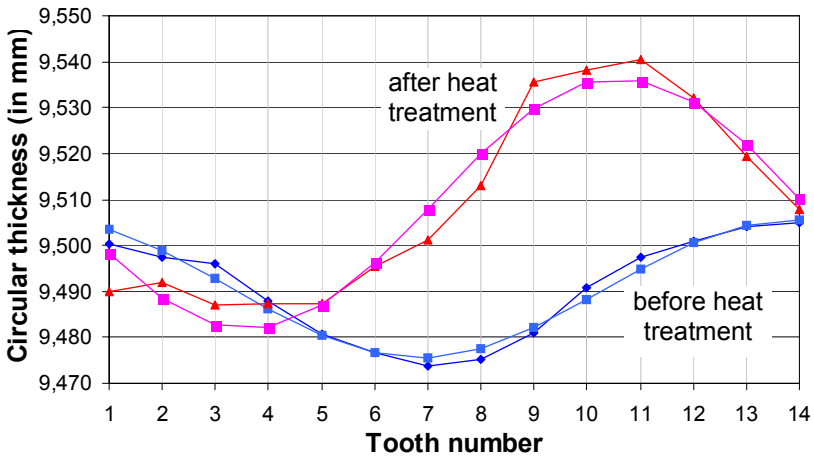

Figure 7: Influence of heat treatment

So we must be careful to the conclusion that we made. To improve the net shape gear, the blacksmith mustn't focalise only on the forging of the teeth but he must work on the integration of the positioning dispersions during tooling operations and effects of heat treatment as far as it's possible in the process planning.

\section{CONCLUSION}

The dimensional control of gear approached by entities enables to characterise more precisely the quality of its functionality. The development of a software model based on our method makes the analysis of all step of the planning process possible, in an industrial context. So developments reported into this presentation put forward the eccentricity of the net shape teeth in regard with the assembly surfaces obtained by tooling, before and after the heat treatment.

This presentation axed on a little part of the process planning, show our method to manage knowledge on a production process. The whole capitalisation of knowledge will enable to diminish the time of development for a part, in our case a net shape gear.

\section{REFERENCES}

[1] Saulau I., Garro O., Martin P., 1995, "Distributed design methodology in the context of concurrent / Concurrent engineering : Research and application A global perspective", ISSN 1076-2868, Paul and Sobolewski Eds 1,232-331

[2] Lee C.H., Sause R, Hong N.K., 1998, "Overview of entity-based integrated design product and process models", Engineering software, vol 29 pp 809-823

[3] Norme NF E 23-001, 1972, "Vocabulaire des engrenages, définitions géométriques. AFNOR

[4] Norme ISO 1328-1, 1995, "Engrenages cylindriques - Système ISO de précision. Partie 1 : Définitions et valeurs admissibles des écarts pour les flancs homologues de la denture", AFNOR

[5] Norme ISO/TR 10064-1, 1996, "Engrenages cylindriques - Code pratique de réception. Partie 1 : Contrôle relatif aux flancs homologues de la denture", AFNOR

[6] Norme DIN 3965, 1986, "Toleranzen für Kegelradverzahnungen : Grundlagen, Toleranzen für Abweichungen einzelner Bestimmungsgrößen", Deutsches Institut für Normung - DIN 
[7] Norme JIS B 1704, 1984, "Accuracy for bevel gears", Japanese Standards Association

[8] Baudouin C., Leleu S., Bigot R. and Coorevits T. 2001, "Contrôle des roues dentées sur machine à mesurer tridimensionnelle - Méthodologie et incertitudes de mesure d'un pignon", $10^{\text {th }}$ international congres of metrology, Saint Louis.

[9] Ballu A., 1993, "Identification de modèles géométriques composés pour la spécification et la mesure par coordonnées des caractéristiques fonctionnelles des pièces mécaniques" Thèse, Université Nancy I

[10] ISO TS 17450-1, 1996, "Geometrical product specification (GPS) - General concepts - Part 1 : Model for geometric specification"

[11] Pfeifer T., Kurokawa S. and Meyer S., 2001, "Derivation of parameters of global form deviations for 3-dimensional surfaces in actual manufacturing processes", Measurement, Vol. 29, pp. 179-200

[12] Correvits T., David J., Bourdet P., 1991, "Elimination of geometrical errors by permutations - application to a rotary table", Annals of the CIRP 